\title{
Subungual haematomas: is simple trephining enough?
}

\author{
S Meek, M White
}

\begin{abstract}
Objectives-To determine the outcome of treating subungual haematomas by simple trephining, in terms of nail appearance and function, and to identify factors associated with a poor outcome.

Methods-Patients with subungual haematomas attending an accident and emergency department over a 12 month period were identified; 5-13 months after injury a telephone and postal survey of patient's assessment of their own outcome was made using a proforma. Outcome was graded according to published criteria.
\end{abstract}

Results-123 patients with 127 subungual haematomas were identified and $74 \%$ were followed up; $85 \%$ achieved an "excellent" or "very good" result, with $67 \%$ reporting no residual abnormalities. A "poor" outcome occurred in only $2 \%$ owing to nail splitting. No correlation was found between adverse outcome and haematoma size, presence of fracture, or infection.

Conclusions-Treatment of subungual haematomas by simple trephining gives an acceptable result in the majority of patients and those with a poor outcome cannot be predicted at presentation. The findings suggest that only simple trephining for symptomatic relief is required for subungual haematomas and that aggressive surgical treatment is unnecessary.

(f Accid Emerg Med 1998;15:269-271)

Keywords: subungual haematoma; nailbed laceration; trephine

Subungual haematomas are traditionally treated symptomatically with simple trephining using a hot paper clip. Recent studies have shown that haematomas involving more than $50 \%$ of the nail surface usually have significant nailbed lacerations. ${ }^{1}$ The incidence of lacerations rises to $94 \%$ when associated with a fracture of the terminal phalanx, irrespective of haematoma size. ${ }^{2}$ It has therefore been suggested that if the haematoma size is more than $25-50 \%$, the nail should be lifted and underlying nailbed lacerations repaired to prevent subsequent nail deformity and to preserve function. ${ }^{1-5}$

There have been no published trials comparing surgical nailbed repair with simple trephining, although a need for such a trial has been expressed. ${ }^{6}$ However, Seaberg ${ }^{7}$ reported no major nail deformities in 43 subungual haematomas treated conservatively. Our aim was to assess outcome in a larger series of patients, with particular reference to size of haematoma and presence of fracture.

\section{Methods}

Patients with upper limb subungual haematomas attending the accident and emergency (A\&E) department at Frenchay Hospital, Bristol, over a 12 month period from November 1994 to October 1995 were identified by computer search, using diagnostic coding for "subungual haematoma," cross checked against "distal phalanx fracture" and "nailbed laceration."

Throughout this period doctors and nurse practitioners in the department had been encouraged to estimate the per cent nail area covered by haematoma. Radiographs of the fingertip were performed at the discretion of individual doctors and the departmental practice was to avoid giving antibiotics to patients with sublingual haematomas, even with a fracture. Infection was defined by clinical criteria and was considered to be present if the patient had received a course of antibiotics. Details such as mode of injury, haematoma size, presence of fracture, sex, and age of the patient were obtained from the A\&E medical notes.

During this period all but two patients with subungual haematomas were treated by trephining. The two that were not were a theatre nurse with a $100 \%$ haematoma and a man with an $80 \%$ haematoma. Neither had an underlying fracture. Both underwent surgical nailbed repair by staff not connected with the $A \& E$ department and were excluded from the study.

Patients were telephoned 5-13 months after the injury and the outcome was assessed using a proforma (fig 1). If nail growth was not complete the patient was contacted again at a later date. This ensured that the healing was complete and any abnormality was permanent. Patients not contactable by telephone were sent a postal questionnaire similar to the telephone proforma.

The proforma identified the presence of major and minor criteria, ${ }^{8}$ which allowed patients to be grouped into one of five categories for outcome (fig 2). Results were evaluated and $\chi^{2}$ analysis performed to determine if any factors were associated with an adverse outcome. 


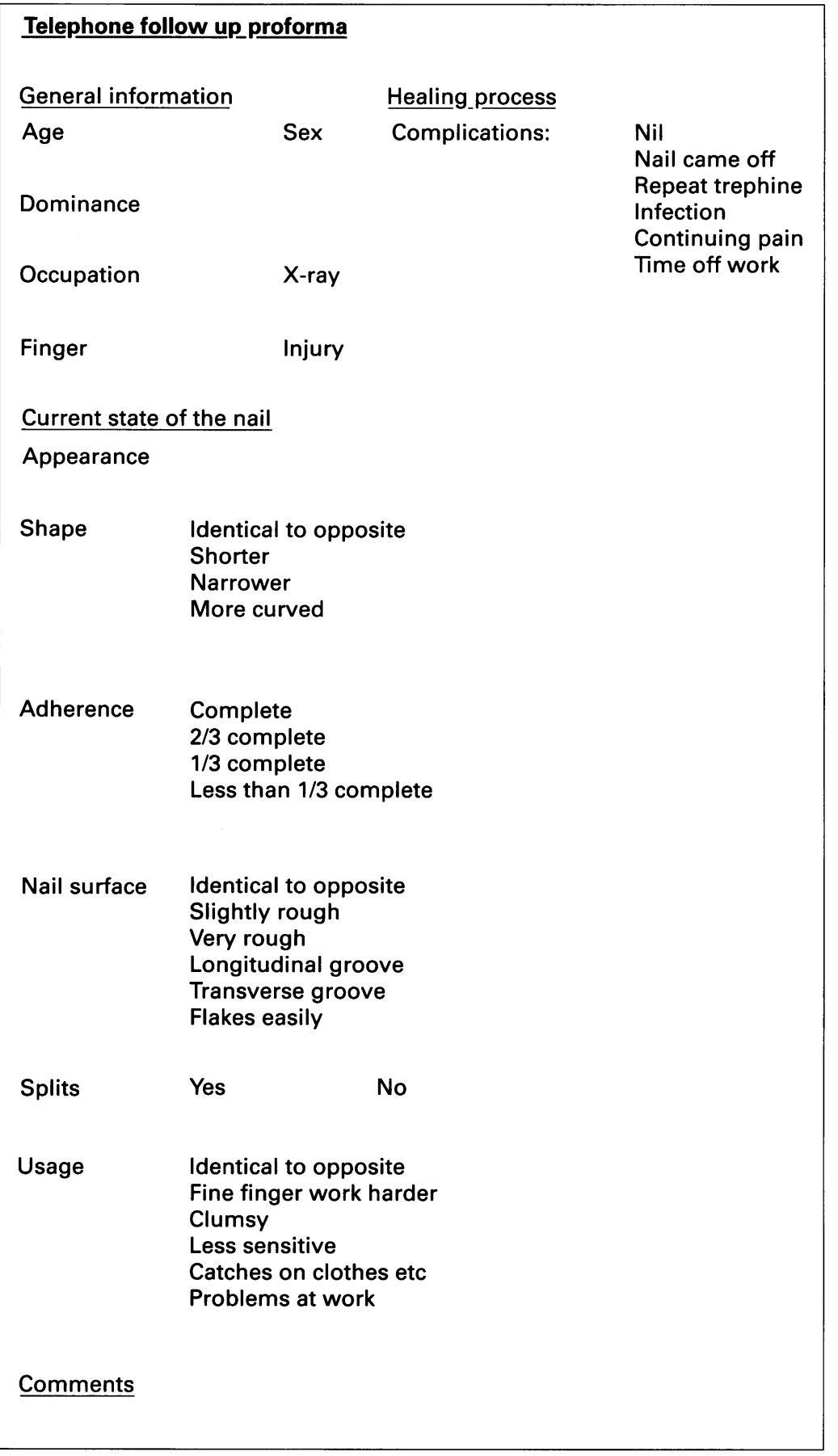

Figure 1 The telephone follow up proforma used in the study.

\section{Results}

We identified 123 patients with 127 subungual haematomas. Ninety four of these were followed up. The median time from injury to follow up was eight months (range 5 to 13 months); $73 \%$ were male, and $36 \%$ of the injuries were caused by crushing in a door.

Left and right hands were injured equally, with thumb and index fingers being most commonly affected. The size of haematoma was recorded in $70 \%$ of cases.

Outcome was "excellent" (that is, no residual abnormality) in $63(67 \%)$, and "very good" in a further $17(18 \%)$. Three $(3 \%)$ were graded as having a "good" and nine (9\%) a "fair" outcome (three minor or one major abnormality), owing to problems such as grooves in the nail, decreased nailbed adher- ence, a narrow or more curved nail. Only two (2\%) had a "poor" outcome, in both cases caused by nail splitting.

SIZE

There was no correlation between size of haematoma and outcome confirmed by a $\chi^{2}$ analysis $(p>0.05)$ (fig 3 ).

\section{FRACTURE}

Radiographs were taken in $67 \%$, of which $52.4 \%$ showed fractures of the distal phalanx (other than tuft fractures). There was no correlation between presence of a fracture and outcome ( $\chi^{2}$ analysis $\left.0.5>\mathrm{p}<0.1\right)$.

\section{INFECTION}

Only five patients reported subsequent infection, yet four of these had an "excellent" result, the other being "very good." It appears there is no association between infection and a worse outcome in this small subgroup of patients.

\section{FUNCTION}

Only five patients reported functional problems. Two of these described sensory changes in the fingertip but no nail abnormality, suggesting symptoms were the result of surrounding soft tissue injury rather than nailbed injury. The remaining three were:

(1) A man aged 54 with $35 \%$ haematoma and underlying fracture describing longitudinal grooves and a more curved nail (a "fair" result). Functional problem: fine finger work was said to be more difficult 10 months after injury.

(2) A woman aged 40 with a "small" haematoma, not $x$ rayed, describing the nail as rough, grooved, and splitting (a "fair" result). Functional problem: catching on clothes nine months after injury.

(3) A woman aged 40 with $75 \%$ haematoma not $x$ rayed, describing decreased adherence of the nail and a slight bump in it. Functional problem: slight fingertip numbness 12 months after injury.

\section{Discussion}

A "major" nail abnormality (assessed by Zook's criteria) occurred in 11 of 94 patients $(11 \%)$ in our series; Seaberg's study ${ }^{7}$ found none in 43 patients, though he did not state his definition of "major" nail abnormality.

In this study assessment of outcome was performed by the patients. Their assessment may be more important than a clinician's since it is the patient who lives with any deformity or functional loss. Additionally, patients are more likely to be sensitive to minor nail abnormalities than an examining doctor. Overwhelmingly, patients were happy with the result, even those with significant deformity. For a male manual worker, a minor abnormality such as a groove in the nail without functional loss is usually of no consequence, and aggressive surgical repair may mean further time off work, for no proven benefit.

Haematoma size and the presence of fracture, although previously shown to corre- 


\begin{tabular}{|c|c|c|c|}
\hline \multicolumn{4}{|l|}{ Zook's outcome criteria } \\
\hline Nail shape & $\underline{\mathrm{Nil}}$ & Minor & Major \\
\hline $\begin{array}{l}\text { Identical to opposite } \\
\text { Shorter } \\
\text { Narrower } \\
\text { Longitudinal curve } \\
\text { Transverse curve }\end{array}$ & * & $\begin{array}{l}* \\
* \\
*\end{array}$ & \\
\hline \multicolumn{4}{|l|}{ Nail adherence } \\
\hline $\begin{array}{l}\text { Complete } \\
2 / 3 \text { complete } \\
1 / 3 \text { to } 2 / 3 \text { complete } \\
\text { Less than } 1 / 3 \text { complete }\end{array}$ & * & * & * \\
\hline \multicolumn{4}{|l|}{ Eponychium } \\
\hline $\begin{array}{l}\text { Identical to opposite } \\
\text { Notched } \\
\text { Synechia }\end{array}$ & * & & $\begin{array}{l}* \\
*\end{array}$ \\
\hline \multicolumn{4}{|l|}{ Nail surface } \\
\hline $\begin{array}{l}\text { Identical to opposite } \\
\text { Slightly rough } \\
\text { Very rough } \\
\text { Longitudinal groove } \\
\text { Transverse groove }\end{array}$ & * & $\begin{array}{l}* \\
* \\
*\end{array}$ & * \\
\hline \multicolumn{4}{|l|}{ Splits } \\
\hline $\begin{array}{l}\text { No } \\
\text { Yes }\end{array}$ & * & & * \\
\hline \multicolumn{4}{|l|}{ Outcome categories } \\
\hline $\begin{array}{l}\text { Excellent = identical to } \\
\text { Very good = } 1 \text { minor def } \\
\text { Good = } 2 \text { minor defects } \\
\text { Fair = } 3 \text { minor or } 1 \text { majo } \\
\text { Poor = more than } 3 \text { min }\end{array}$ & $\begin{array}{l}\text { nail } \\
\text { najor }\end{array}$ & & \\
\hline
\end{tabular}

Figure 2 Outcome categories according to Zook. ${ }^{8}$

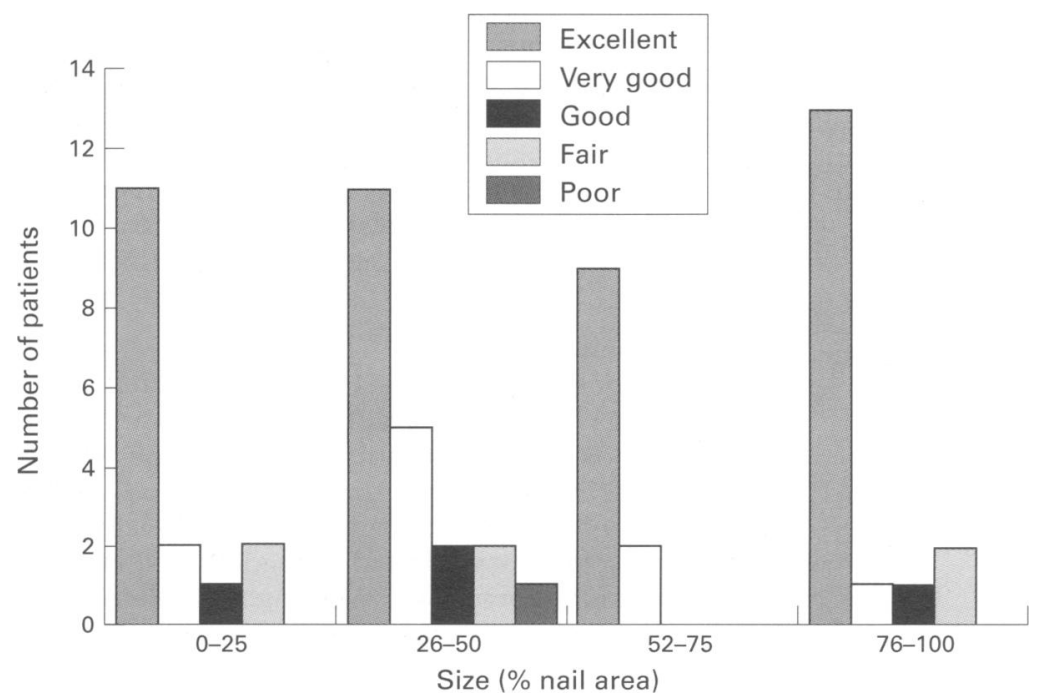

Figure 3 Outcome in different sized haematomas. late with the presence of nailbed laceration, ${ }^{2}$ did not lead to an increased risk of nail deformity or functional loss in our study. Thus it is not currently possible to predict patients at risk of a poor outcome at presentation, and all patients should be warned that nail deformity may occur.

\section{Conclusions}

Treating subungual haematomas for symptomatic relief with simple trephining produces an "excellent" or "very good" result in $85 \%$ of patients, and outcome is not related to size of haematoma or the presence of a fracture.

As the small number of patients at risk of a poor outcome cannot currently be identified at presentation and there is no evidence that surgical nailbed repair improves outcome, we believe that trephining alone is adequate treatment for all subungual haematomas.

We wish to thank Paul Ewings (Taunton and Somerset NHS Trust) for statistical help.

Van Beek AL, Kassan MA, Adson MH, et al. Management of acute fingernail injuries. Hand Clinics 1990;6:23-35.

Simon $R$, Wolgin $M$. Subungual haematoma: association with occult laceration requiring repair. Am J Emerg Med 1987;5:302-4.

3 Klienert H, Putcha S. The deformed fingernail, a frequent result of failure to repair nailbed injuries. J Trauma 1967;7: 177-90.

4 Zook EG. Injuries of the finger nail. In: Green D, ed. Operative hand surgery. New York: Churchill Livingstone, tive hand surgery. New York: Churchill Livingstone, 1988:895-914.

one CP, Grad JB. Primary care of fingernail injuries. Emerg Med Clin North Am 1985;3:255-61.

6 Hedges JR. Subungual haematoma. Am J Emerg Med 1988;6:85.

Seaberg D, Angelos W, Paris P. Treatment of subungual haematomas with nail trephination: a prospective study. Am J Emerg Med 1991;9:209-10.

8 Zook EG, Guy RJ, Russell RC. A study of nailbed injuries: causes, treatment and prognosis. J Hand Surg (Am) 1984; 9A:247-52. 